DOI: $10.14451 / 1.204 .199$

\title{
СОВРЕМЕННЫЙ МЕХАНИЗМ ВЗАИМОДЕЙСТВИЯ ЧАСТНОГО ПАРТНЕРА И ГОСУДАРСТВА В ПРОЕКТАХ СТРОИТЕЛЬСТВА ТРАНСПОРТНО- ПЕРЕСАДОЧНЫХ УЗЛОВ, КАК ИНСТРУМЕНТ ПОВЫШЕНИЯ ЭКОНОМИЧЕСКОЙ БЕЗОПАСНОСТИ
}

\author{
(C) 2021 Абрамян Артур Эдикович \\ аспирант кафедры экономика транспортной инфраструктуры и управления строительным бизнесом \\ Российский университет транспорта, Россия, Москва \\ E-mail: abramyanae@to50reg.ru \\ (c) 2021 Капустина Надежда Валерьевна \\ доктор экономических наук, доцент, профессор департамента экономической безопасности и \\ управления рисками \\ Финансовый университет при Правительстве Российской Федерации, Россия, Москва \\ E-mail: kuzminova_n@mail.ru \\ () 2021 Кузьменко Юлия Алексеевна \\ кандидат юридических наук, доцент кафедры финансового права \\ Российский государственный гуманитарный университет (РГГУ), Россия, Москва \\ E-mail: Julkuzmenko@yandex.ru
}

Автором данной статьи рассмотрена модель взаимодействия коммерческого партнера и государства при строительстве транспортно-пересадочных узлов на территории г. Москва. На примере ТПУ «Хорошевская» проанализированы функции участников проекта и сформирована сложившаяся схема взаимодействия. Сделан вывод о рисках действующей схемы и внесены предложения по ее совершенствованию.

Ключевые слова: государственно-частное партнерство (ГЧП), транспортно-пересадочный узел (ТПУ), концессия, инфраструктура, контракт.

«Потребности России в инфраструктурных инвестициях до 2020 года оцениваются в 78 трлн. руб. Для развития транспортной инфраструктуры необходимо 64\% из них» - сообщает специалист из Forbes Игорь Снегуров [10].

Эффективный способ решения проблемы инфраструктурной недостаточности - ГЧП (государственно-частное партнерство) - взаимовыгодное средне- и долгосрочное сотрудничество государства и частного партнера, реализуемое в различных формах [6]. По данным Центра развития ГЧП, в России с помощью данного механизма реализуется приблизительно 2400 проектов, - общим объемом инвестиций более 1,5 трлн. руб. [8].

Механизм позволяет успешно решать инфраструктурные проблемы во всем мире. Концессионные схемы взаимодействия давно применяются и в нашей стране: $70 \%$ железных дорог в Российской империи были построены в рамках концессионных соглашений [10].
Пример современного проекта ГЧП мировой значимости - космический проект Илона Маска Space X, который реализуется при софинансировании фонда развития инфраструктуры США. Если обратить внимание на развитые экономики мира, то можно отметить, что фонд развития инфраструктуры в США составляет \$200 млрд., в Китае - \$600 млрд.

В России государственно-частное партнерство регулируется следующими нормативноправовыми актами:

- ФЗ от 21.07.2005 № 115-Ф3 «О концессионных соглашениях» [1];

- ФЗ от 13.07.2015 № 224-Ф3 «О государственно-частном партнерстве, в Российской Федерации» [2];

- Ф3 от 05.04.2013 № 44-Ф3 «О контрактной системе в сфере закупок товаров, работ, услуг для обеспечения государственных и муниципальных нужд» [3];

- Ф3 от 30.12.1995 № 225 «О соглашениях о 
разделе продукции» [4].

В общем виде схема ГЧП и концессий выглядит следующим образом: объект инфраструктуры строится и эксплуатируется за счёт собственных и заёмных средств частного партнёра и передаётся субъекту Федерации «под ключ», после чего последний расплачивается за него в течение определённого периода. Перенос риска создания объекта на сторону частного партнёра - гарантия того, что объект будет построен и построен качественно: от этого зависит возврат вложенных в проект инвестиций.

В диссертации А. Ю.Добрина выделены формы партнерства между государством и частным бизнесом, показанные на рисунке 1 [5].

Государственные (муниципальные) контракты - краткосрочные контракты, заключаемые муниципальными образованиями с целью обеспечения государственных или муниципальных нужд;

Арендные (лизинговые) отношения - вид партнерства государства и частного бизнеса, возникающий при передаче государством в аренду частному сектору своей собственности;
Соглашение о разделе продукции (СРП) - предоставление частному партнеру на возмездной основе на определенный срок исключительных прав на поиски, разведку, добычу минерального сырья на участке недр, указанном в соглашении. Частный партнер осуществляет указанные работы за свой счет, принимая все риски, и делится произведенной продукцией с государством;

Государственно-частное предприятие предполагает участие частного сектора в капитале государственного предприятия путем акционирования и создания совместных предприятий.

Концессия - система отношений между государством (концедентом) и частным юридическим или физическим лицом (концессионером), возникающая в результате предоставления концедентом концессионеру прав пользования государственной собственностью по договору, за плату и на возвратной основе, а также прав на осуществление видов деятельности, которые составляют исключительную монополию государства.

Контракт жизненного цикла (КЖЦ) - новая

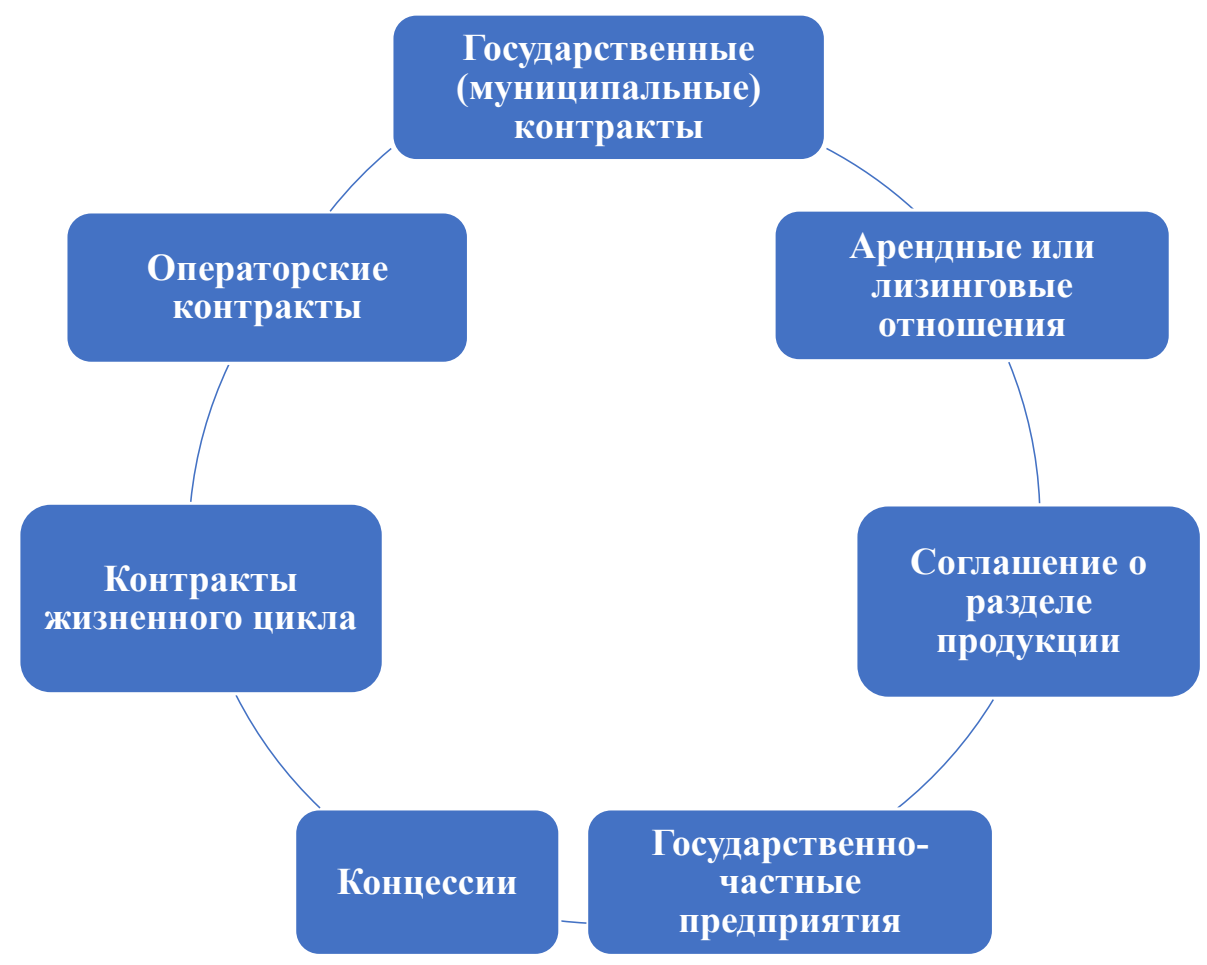

Рис. 1. Классификация ГЧП в России [6] 
схема ГЧП, представляющая собой систему долгосрочных договорных отношений между государственными и частными контрагентами с привлечением заемного финансирования. Как правило, КЖЦ заключается на весь комплекс работ, связанных с проектированием, строительством, финансированием и содержанием объекта.

Операторские контракты - применяются в случае, если объект построен, но необходимо профинансировать создание дополнительных элементов инфраструктуры и оперативного управления объектом (например, система взимании платы за проезд) [5].

В рекомендациях Центра развития ГЧП по реализации проектов государственно-частного партнерства в субъектах РФ приведены формы взаимодействия, показанные на рисунке 2 [9].

В рамках настоящего исследования особый интерес представляют механизмы взаимодействия участников строительства транспортнопересадочных узлов (далее по тексту - ТПУ). Таким проектам характерно наличие как технологической части (крытых переходных галерей, пассажирских платформ и перронов), так и коммерческой части, которая используется для сни- жения финансовой нагрузки на муниципальные бюджеты путем привлечения коммерческого партнера к реализации проекта ТПУ. При этом, организационная схема взаимодействия партнеров в таких проектах может отличаться от классических, прямо предусмотренных вышеуказанными законами.

В качестве примера реализации проекта транспортно-пересадочного узла по форме ГЧП может быть рассмотрен проект ТПУХорошевская. Согласно конкурсной документации к открытому конкурсу на право заключения договора купли-продажи 99,9\% доли в уставном капитале ЗАО «ТПУ «Хорошевская», организатор конкурса в лице $\mathrm{AO}$ «Мосинжпроект» обязуется: - обеспечить оформление договора аренды земельных участков общей площадью не более 1,37 га между $3 \mathrm{AO}$ «ТПУ «Хорошевская» и Департаментом городского имущества города Москву на срок не менее 6 лет с функциональным назначением участков: участок смешанного общественнопроизводственного вида, предназначенный для размещения многофункционального центра ТПУ, ориентировочной площадью 42321 кв.м., участок административно-делового вида для размещения здания общественно-делового на-

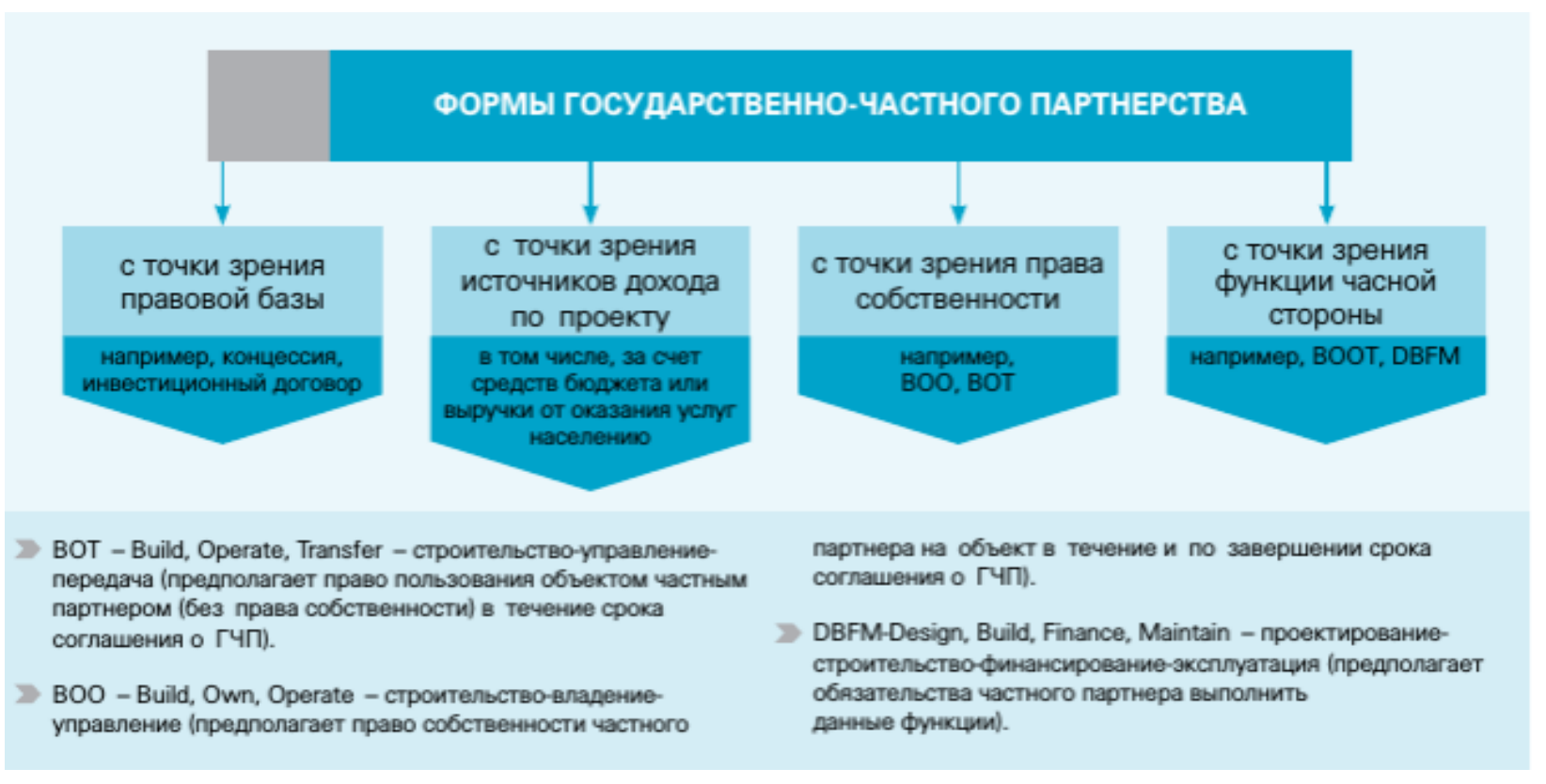

Puc. 2. Основные направления ГЧП [8] 
значения с подземной парковкой, ориентировочной площадью 27470 кв.м., что подтверждается градостроительным планом на земельный участок, и ставкой арендной платы в размере, определяемом в соответствии с законодательством Российской Федерации об оценочной деятельности.

Победитель конкурса (покупатель), в свою очередь гарантирует и обязуется:

1. произвести платежи по договору купли продажи акций в установленный срок;

2. на земельных участках, предназначенных под строительство ТПУ «Хорошевская», в течение срока аренды произвести за свой счёт застройку коммерческими объектами капитального строительства с сопутствующей инфраструктурой в соответствии с техникоэкономическими параметрами, предусмотренными в Проекте планировки территории;

3. за свой счет в порядке и сроки, установленные Проектом планировки территории и в Графике реализации технологической части ТПУ, выполнить проектирование, строительство, ввод в эксплуатацию и передачу на безвозмездной основе в собственность г. Москвы капитальных объектов технологической части ТПУ в составе и ориентировочной площадью: диспетчерская с залом ожидания и кассовая зона метро -2533 кв.м. [7].

Таким образом, схема реализации транспортно-пересадочных узлов отличается от классических форм государственно-частного партнерства и не поддаётся однозначной классификации, однако имеет схожие характеристики с такими формами как:

- арендные отношения, в связи с передачей государством частному сектору своей собственности в аренду (земельные участки) и взимание соответствующей платы;

- государственно-частное предприятие, в связи с продажей государством частному сектору акций проектной компании;

- концессия, в связи с обязательством частного партнера построить и эксплуатировать за свой счет объект недвижимости, права на который принадлежат государству.
Схематичный вариант действующего механизма взаимодействия частного инвестора и государства в рамках реализации проектов транспортно-пересадочных узлов на примере ЗАО «ТПУ «Хорошевская» приведен на рисунке 3.

Изученная в настоящем исследовании организационная схема взаимодействия может быть использована при реализации таких проектов ТПУ, дизайн-проектом которых предусмотрено совмещение технологической и коммерческой части в границах одного здания (интегрированное ТПУ, коммерческая и технологическая части которого размещены на одном земельном участке и неотделимы друг от друга). В таком случае является логичным передача обязательств по строительству технологической части коммерческому партнеру проекта (покупателю, победителю конкурса). Однако, проект планировки территории также предполагает застройку коммерческими объектами, прилегающими, но не интегрированными в технологическую часть. При этом, автором сделана следующая рекомендация: в случае использования данной схемы муниципальному партнеру следует всесторонне регламентировать требования к качеству, параметрам и срокам строительства технологической части ТПУ и ретранслировать их коммерческому партнеру в комплекте аукционной документации. Следует обязать коммерческого партнера декларировать приоритет строительства технологической части ТПУ для снижения риска возникновения «долгостроя» на транспортной сети агломерации.

Учитывая вышеуказанные риски, автором сделано предложение не включать строительство технологической части ТПУ в перечень обязательств коммерческого партнера, если с экономической точки зрения возможно строительство коммерческой части ТПУ на отдельном земельном участке в качестве самостоятельного титула проектирования. Это позволит существенно снизить риски несвоевременного ввода в эксплуатацию технологической части ТПУ и, следовательно, приведет к динамичному развитию транспортной сети и прилегающих к ней территорий агломерации. 


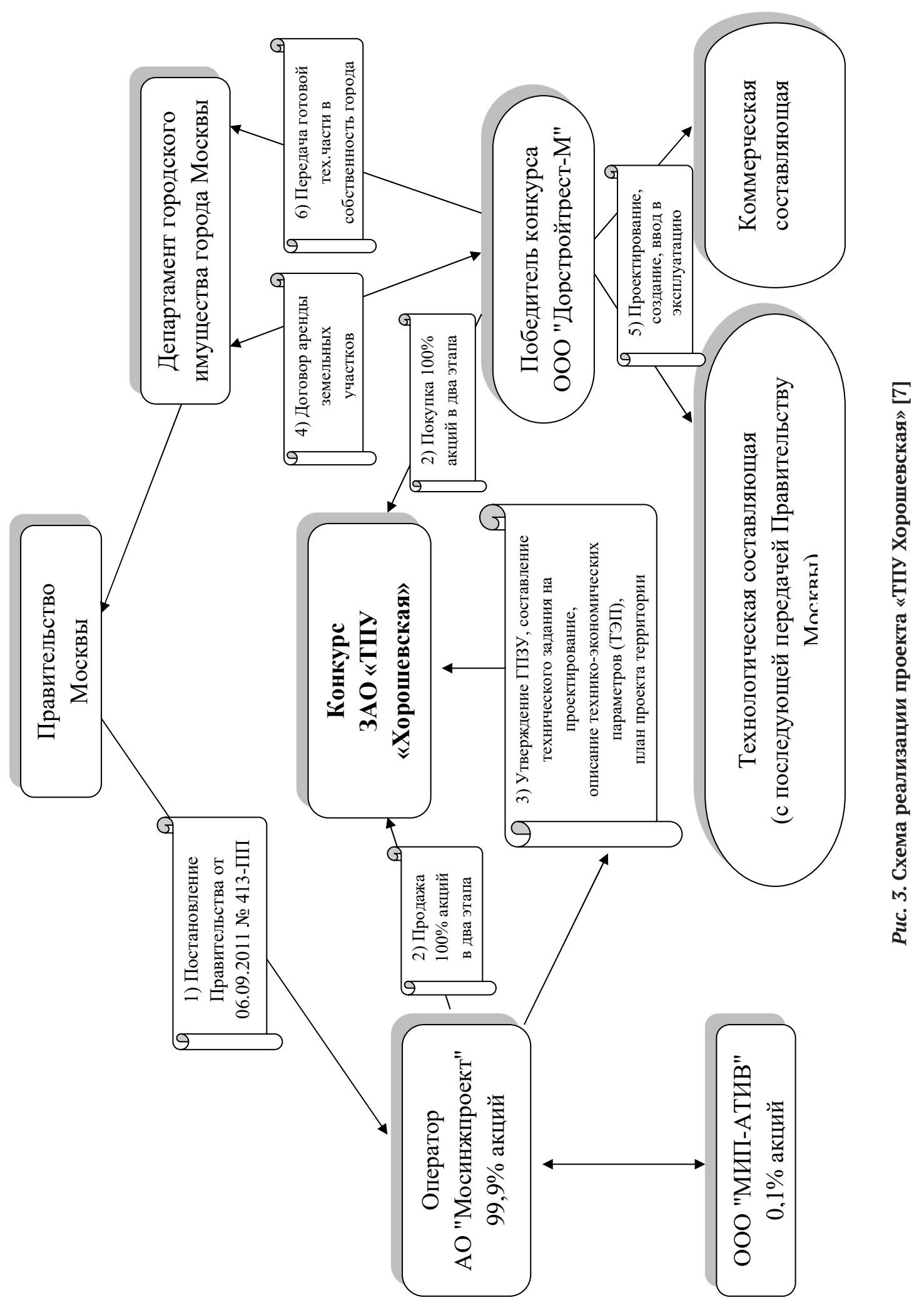




\section{Библиографический список}

1. Федеральный закон от 21.07.2005 № 115-Ф3 «О концессионных соглашениях»

2. Федеральный закон от 13.07.2015 № 224-Ф3 «О государственно-частном партнерстве, муниципальночастном партнерстве в Российской Федерации»

3. Федеральный закон от 05.04.2013 N 44-Ф3 «О контрактной системе в сфере закупок товаров, работ, услуг для обеспечения государственных и муниципальных нужд».

4. Федеральный закон от 30.12.1995 № 225 «О соглашениях о разделе продукции».

5. Добрин А.Ю. «Экономическое обоснование механизмов государственно-частного партнерства в транспортном строительстве». Диссертация на соискание ученой степени кандидата экономических наук, 153 стр.

6. Добрин А.Ю. ГЧП в транспортной отрасли // А.А. Гавриленков, А. Ю. Добрин, В. В. Чуликов// Мир транспорта. 2012. - № 1. -С.96-101.

7. Инвестиционный портал города Москвы. https://investmoscow.ru/tenders/tendercard/? TenderId=17003991.

8. Национальный центр государственно - частного партнерства. http://pppcenter.ru/proektyi-czentra/bazaproektov-gchp.html

9. Национальный центр развития ГЧП «Рекомендации по реализации проектов ГЧП в субъектах РФ», Москва, 2013 г.

10. Снегуров И. Инфраструктурная недостаточность: почему дороги и больницы в России строятся медленно и стоят дорого// Снегуров И.// Электронный журнал Forbes. 2017. - 7 стр. 